Article

\title{
Evaluation of Precipitation Climatology Derived from TRMM Multi-Satellite Precipitation Analysis (TMPA) Monthly Product over Land with Two Gauge-Based Products
}

\section{Zhong Liu}

Center for Spatial Information Science and Systems (CSISS), George Mason University, 4400 University Drive, Fairfax, VA 22030, USA; E-Mail: zliu@ gmu.edu; Tel.: +1-301-614-5764.

Academic Editor: Menglin Susan Jin

Received: 3 April 2015 / Accepted: 27 October 2015 / Published: 18 November 2015

\begin{abstract}
The NASA/JAXA Tropical Rainfall Measuring Mission (TRMM) has been in operation for over 17 years since 1997. The length of TRMM is far shorter than those from ground observations, raising a question as to whether TRMM derived climatology products are good enough for research and applications. In this study, three climatologies derived from a blended product (the TRMM Multi-Satellite Precipitation Analysis (TMPA) monthly product or 3B43) and gauge-based ground observations (Global Precipitation Climatology Center (GPCC) and Willmott and Matsuura (WM)) are compared over land on a global scale $\left(50^{\circ} \mathrm{N}-50^{\circ} \mathrm{S}\right)$ to assess the performance and weaknesses of the TMPA-derived climatology. Results show that the 3B43 climatology matches well with the two gauge-based climatologies in all seasons in terms of spatial distribution, zonal means as well as seasonal variations. However, large variations are found in light rain $(<0.5 \mathrm{~mm} /$ day $)$ regions such as the Sahara Desert. At high rain rates, large negative biases (3B43 < WM $<$ GPCC) are found in orographically influenced regions such as windward sides of monsoon mountains in JJA, which is associated with underestimation of shallow orographic rain rates in microwave radiometer algorithms and sparse gauge data for bias correction. Nonetheless, biases in 3B43 exist and vary with geographic locations due to a number of factors such as gauge availability and algorithm issues.
\end{abstract}

Keywords: climatology; precipitation; TRMM; gauges; satellites; comparisons; droughts 


\section{Introduction}

Precipitation is a very important physical variable in our daily lives [1]. However, as a double-edged sword, droughts and floods can occur each year in different regions around the world [2-4], often causing considerable damage to crops, properties, human fatalities, etc. In addition to precipitation, derived anomaly information can be useful in drought detection, monitoring and management activities by providing additional information compared to the normal condition which is also known as climatology. Precipitation is notoriously difficult to measure and forecast both over land and ocean. In remote regions such as mountains, deserts, etc. it is difficult to obtain precipitation information from ground measurements. Satellite-based precipitation products take an increasingly important role in filling data gaps in those regions and are widely used in research and decision support or monitoring applications.

In recent years, precipitation products that utilize multi-satellite and multi-sensor datasets have been gaining more and more popularity than products from a single sensor or satellite. Adjusted for bias with gauge and ground radar products, satellite-based precipitation products have been significantly improved over the years. An example is the TRMM Multi-Satellite Precipitation Analysis (TMPA) monthly product (3B43), a popular near-global $\left(50^{\circ} \mathrm{N}-50^{\circ} \mathrm{S}\right)$ precipitation product that is widely used around the world. However the history of satellite precipitation products is relatively short compared to the length of 30 years in the World Meteorological Organization (WMO) definition for climatology. For example, the NASA/JAXA (Japan Aerospace Exploration Agency) Tropical Rainfall Measuring Mission (TRMM) [5,6] has been in operation for over 17 years since 1997. The length of TRMM is far shorter than those from ground observations, raising a question as to whether TRMM-derived climatology products are good enough for research and applications.

Previously, there have been a few efforts to compare and evaluate TRMM-derived climatologies [7,8]. Based on surface types, Wang et al. [8] compared the TRMM Composite Climatology (TCC) with several other datasets. Over ocean, TCC consists of the data products from TRMM Microwave Imager (TMI, 2A12), TRMM Precipitation Radar (PR, 2A25), and the combined TMI and PR (2B31). Data from atolls were used for comparison. Over land, the TMPA monthly product (3B43) is picked for TCC and surface observations from the Global Precipitation Climatology Center (GPCC) were used for comparison. However, the study areas over land from Wang et al. [8] are only limited to the southeastern United States and eastern China. No information on seasonal variations is provided as well. Furthermore, the study domain is limited to the TRMM coverage $\left(38^{\circ} \mathrm{N}-38^{\circ} \mathrm{S}\right)$, but in fact, the full spatial coverage of 3B43 is between $50^{\circ} \mathrm{N}-50^{\circ} \mathrm{S}$. Some of the regions outside the TRMM coverage are heavily populated such as southern Europe. Including such regions can be helpful for research and applications as well. Therefore, to better understand how TMPA 3B43 performs in the rest of the world and in different seasons, additional studies are needed. In this study, two climatology products from gauge-based observations are compared with the TMPA 3B43 climatology to assess the performance and weaknesses of the satellite-based climatology product. Furthermore, this study looks into ancillary data to explain biases found in the comparison. It needs to be emphasized that validation or verification of satellite-based precipitation products still heavily relies on individuals who often can obtain ground measurements with higher spatial and temporal resolutions than those from GPCC. For such reason, this study is not intended for ground validation for 3B43 and the task should be left to those individual 
investigators. This article is organized as, Section 2 describes the data; Section 3 the results and Section 4 summary and discussion.

\section{Data}

Three global monthly precipitation products (to derive their climatologies) were used in this study. Table 1 summarizes the basic information.

Table 1. Monthly precipitation products used in this study. As of this writing, the 3B43 monthly product for December 2014 was not available.

\begin{tabular}{cccc}
\hline Product & Data Sources & Spatial Resolution & Spatial Coverage \\
\hline TMPA 3B43 Monthly & Satellites and gauges (blended) $(1998-2013)$ & $0.25 \mathrm{deg} . \times 0.25 \mathrm{deg}$. & $50^{\circ} \mathrm{N}-50^{\circ} \mathrm{S}$ \\
Precipitation Version 7 & WMO GTS (Global Telecommunication & & \\
GPCC 2011 & System) gauges and historical data (1951-2000) & $0.25 \mathrm{deg} . \times 0.25 \mathrm{deg}$. & $90^{\circ} \mathrm{N}-90^{\circ} \mathrm{S}$ \\
Precipitation Climatology & GHCN (Global Historical Climatology & $0.5 \mathrm{deg} . \times 0.5 \mathrm{deg}$. & $90^{\circ} \mathrm{N}-90^{\circ} \mathrm{S}$ \\
Willmott and Matsuura (WM) & Network) gauges (1950-1999) & (regridded to 0.25 deg.) & \\
Monthly Precipitation Version 1.02 & & & \\
\hline
\end{tabular}

The purpose of the Version 7 TMPA 3B43 algorithm [9-12] is to produce the best-estimate precipitation rate and root-mean-square (RMS) precipitation-error estimates from TRMM and other data sources. The 3B43 algorithm [9-12] consists of multiple independent precipitation estimates from the TMI (TRMM Microwave Imager), Advanced Microwave Scanning Radiometer for Earth Observing Systems (AMSR-E), Special Sensor Microwave Imager (SSMI), Special Sensor Microwave Imager/Sounder (SSMIS), Advanced Microwave Sounding Unit (AMSU), Microwave Humidity Sounder (MHS), microwave-adjusted merged geo-infrared (IR), and monthly accumulated rain gauge analysis from GPCC for bias correction.

The preprocessing [12] of 3B43 is as follows: (a) all input microwave products mentioned above are intercalibrated to TRMM Combined Instrument (TCI) precipitation estimates (TRMM product 3B31); (b) the IR estimates are computed using monthly matched microwave-IR histogram matching; (c) then missing data in individual 3-hourly merged-microwave fields are filled with the IR estimates. When the preprocessing is complete, the 3-hourly multi-satellite fields are summed for the month and combined with the monthly gauge analysis using inverse-error-variance weighting to form the best-estimate precipitation rate and RMS precipitation-error estimates [12].

According to Huffman [9], the accuracy of 3B43 can be broken into two parts, systematic and random departures from the true answer. The former is also called bias and the latter random error [9]. Random errors can be averaged out in climatological averages; however for bias, it is not the case and it cannot be averaged out in climatological averages, posing the biggest problem for climate studies and applications. In this study, the bias issue is the main concern since random errors have been averaged out during climatological averages. Furthermore, the 3B43 ancillary data (i.e., gauge weight) are analyzed to gain insight on biases.

There were only a few issues [13] in Version $63 \mathrm{~B} 43$, such as a V-shape trough in the global averaged time series, which has been largely corrected in Version 7. Version 7 3B43 data in this study were downloaded from Mirador [14] at the NASA Goddard Earth Sciences Data and Information Services 
Center (GES DISC). There have been a few processing issues [12] before, but all the 3B43 data used in this study are current.

The Version 1.02 Willmott and Matsuura (WM hereafter) global land-only monthly precipitation dataset [15] was developed based on the Version 2 Global Historical Climatology Network (GHCN) and Legates and Willmott's station records $[16,17]$ of monthly and annual mean total precipitation. The Version $3 \mathrm{GHCN}$ is currently available, but the WM monthly product has not been updated yet and in this study, Version 1.02 is used instead. There were 20,599 GHCN stations, varying from about 1870 to 16,360 , used for the precipitation dataset. The DEM-assisted Legates and Willmott archive [18] (Version 2.02) was used as the background field for the Climatologically Aided Interpolation (CAI) and the traditional interpolation algorithm is based on the spherical version of Shepard's distance-weighting method [19,20]. For this study, the $0.5 \mathrm{deg}$. WM dataset was regridded to $0.25 \mathrm{deg}$., using a box average method, to match the spatial resolution of the other two datasets.

The Version 2011 monthly land-surface precipitation climatology [21] from GPCC was derived from rain-gauges built on WMO GTS (Global Telecommunication System)-based and historic data. The climatology [21] is based on the 67,200 stations world-wide that feature record durations of 10 years or longer, for the target reference period between January 1951 and December 2000. Meyer-Christoffer et al. [21] used earlier or later data records of 10 years or longer if no station data were available for the target period, thereby yielding a high station density and temporal stability for the climatology.

To facilitate intercomparison of these climatologies, the NASA GES DISC has developed an online intercomparison tool [22] in the TRMM Online Visualization and Analysis System (TOVAS) [13,23,24], as a member of the GES DISC Geospatial Interactive Online Visualization ANd aNalysis Infrastructure (Giovanni) [23,25-27]. Giovanni is an online or web-based application that provides a simple and intuitive way to visualize, analyze, and access vast amounts of Earth science remote sensing data mainly archived at the GES DISC without having to download data and software. Basic and customized comparison tasks (i.e., scatter plot, correlation, time series, histogram, etc.) can be done in TOVAS [13] or through offline analysis by downloading customized data from TOVAS. Because it is difficult to cover every place on Earth in this study and 3B43 biases vary with geographic locations, it is encouraged to use the online tool for comparison in one's own area of interest. For this study, all comparisons were done offline because not all the analytical functions are available in TOVAS.

\section{Results}

Evaluation of the 3B43 climatology on a global scale was done by comparing two gauge-based climatologies. Ensemble statistics [28], zonal means, scatterplots and Pearson's correlation coefficients were computed in four seasons. Biases against gauge measurements were estimated in different seasons as well as at different rain rates. Gauge weighting in 3B43 as one of the possible influencing factors is analyzed to explain differences in comparisons.

\subsection{Ensemble Statistics, Pearson's Correlation Coefficients, Gauge Weighting and Zonal Means}

To understand the differences among the three climatologies, means (by averaging rain rates in three products) and relative (to the ensemble mean) standard deviations are computed for each season as a 
three-member ensemble [28]. Seasonal ensemble mean maps are shown in Figure 1. It is seen that the major monsoon regions in the Tropics and sub-tropics such as the Asian monsoons, the African monsoons, and their seasonal changes are adequately shown in the rainfall ensemble maps (Figure 1). Heavy rain regions are concentrated in the Tropics. Regions of heaviest rainfall are found in orographically influenced regions such as along the coasts of southwest India, Burma (Myanmar), etc. where the orographic uplifting effect takes an important role in producing heavy precipitation on the windward sides. Seasonal variations are also shown in Figure 1 where heaviest rainfall regions are found in the summer (JJA) monsoon regions in the Northern Hemisphere and in contrast, little rain is received there during boreal winter (DJF).

a)

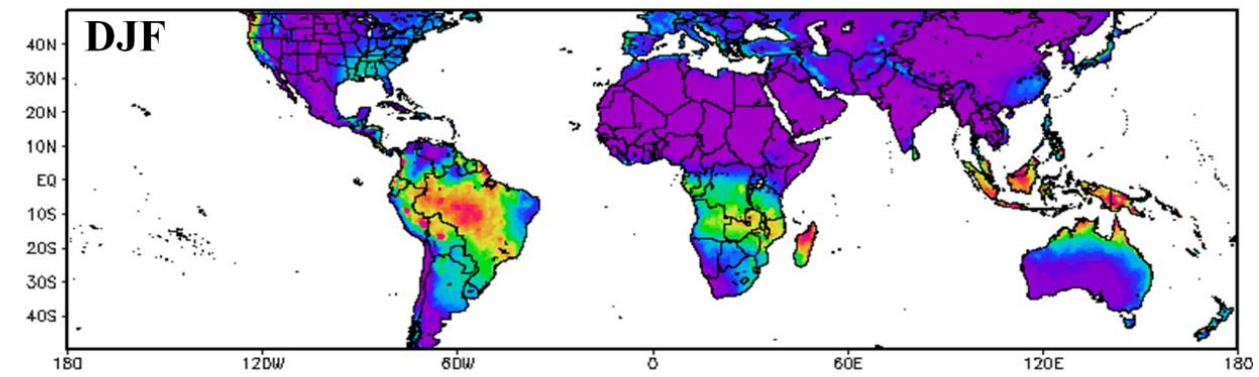

b)

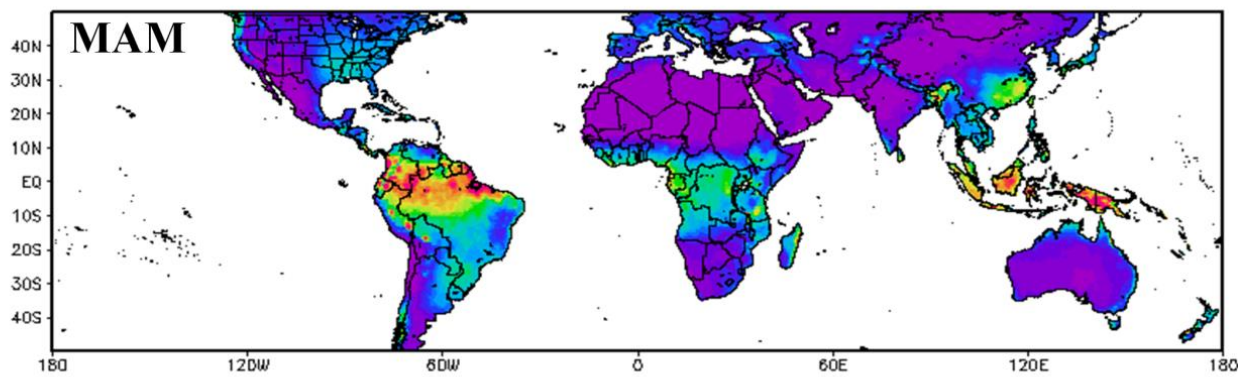

c)

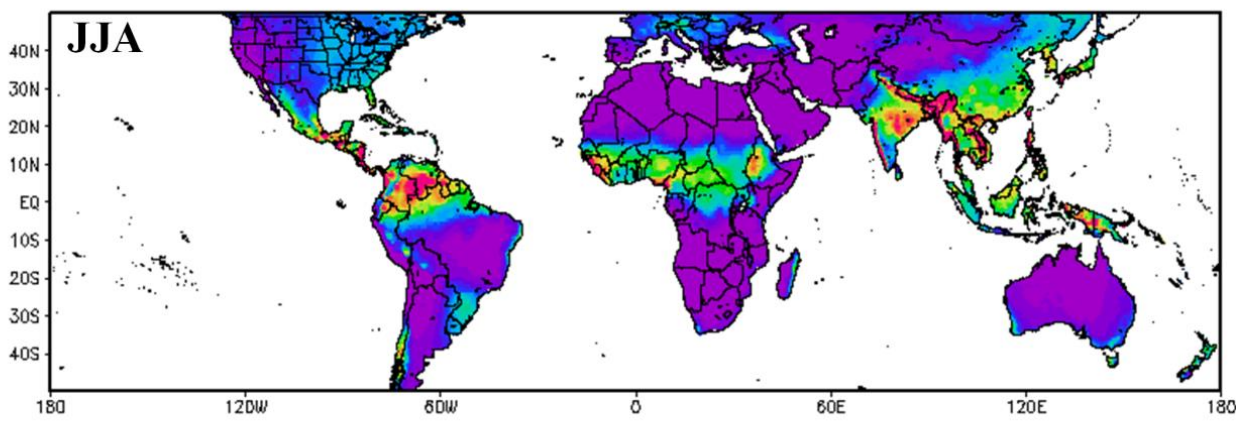

d)

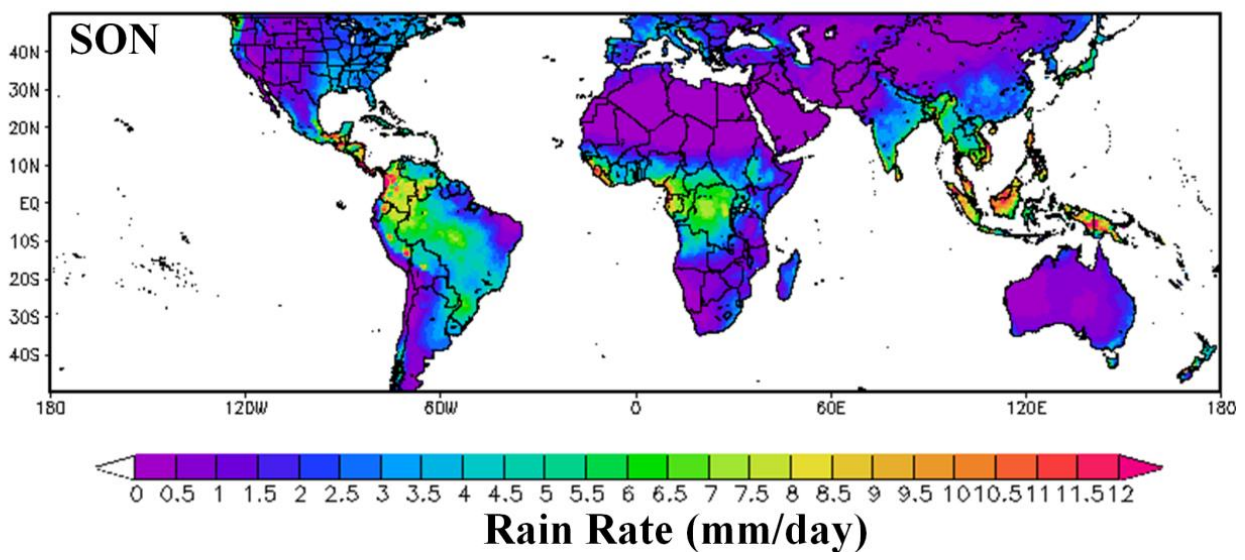

Figure 1. Mean seasonal precipitation (mm/day) of the 3-member ensemble for (a) DJF; (b) MAM; (c) JJA; and (d) SON. 
Figure 2 contains the maps of seasonal relative (with respect to or divided by the ensemble mean in Figure 1) standard deviations in percentage. In general, small variations $(<\sim 15 \%)$ are found in major monsoon regions or regions with moderate amount of rainfall (see Figure 1); however, in some heavy monsoon rain regions such as the coasts of southwest India, northwest Colombia, etc. variations are over $30 \%$ in JJA (Figure 2), suggesting the variations in rainfall estimates there are quite large and uncertain. More will be discussed in later sessions.

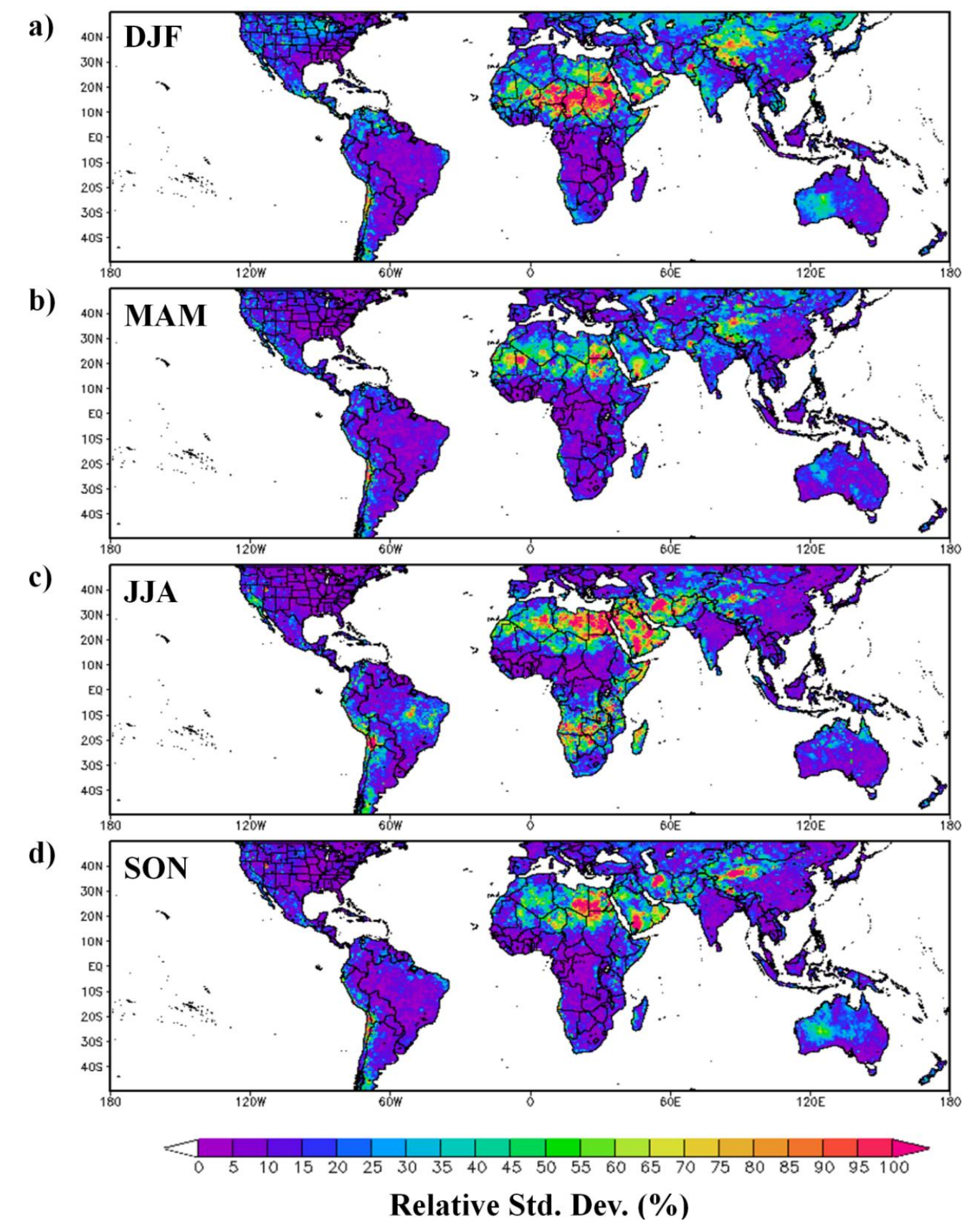

Figure 2. Similar to Figure 1, except for relative (to the ensemble mean in Figure 1) standard deviation in percentages (\%). (a) DJF; (b) MAM; (c) JJA; and (d) SON.

Large variations $(>15 \%)$ in standard deviation are also found in light rain (rain rate $<0.5 \mathrm{~mm} /$ day, Figure 1) regions that mainly consist of remote, less populated and mountainous regions such as the Sahara Desert, the Arabian Peninsula, the Tibetan Plateau, the Andes, etc. It is worth noting that light 
rain rate here does not mean light rain events in those regions. More on this will be discussed later. Variations in those regions can exceed over $90 \%$ in all seasons (Figure 2). In boreal winter (DJF), the regions of large variations extend further north in the Northern Hemisphere compared to JJA, in regions such as the northern Eurasia, northwest United States (Figure 2). In boreal summer (JJA), the most prominent region (Figure 2c) is southern Africa, which does not show up in the other three seasons. Large variations are found in Western Australia in all seasons, especially in SON and DJF. Further investigation reveals that large variations are found between the two ground-based climatologies as well (not shown). More on this will be discussed next. In short, 3B43 behaves well compared to the other two climatologies in regions with rain rates that are above $0.5 \mathrm{~mm} /$ day.

Figure $3 \mathrm{a}$ is generated to understand the relationship between relative standard deviation and ensemble rain rate on a global scale in four seasons. Due to larger variations associated with light rain, as mentioned earlier, only rain rates that are greater than $0.5 \mathrm{~mm} /$ day are plotted. In Figure 3a, it is seen that in SON, DJF, and MAM, the maximum available rain rate is $25 \mathrm{~mm}$ /day which is much lower than that (40 mm/day) in JJA. Meanwhile, the relative standard deviations in the three seasons are fluctuating and are confined between $\sim 7 \%$ and $\sim 13 \%$ of the ensemble mean. In contrast, in JJA, the relative standard deviation first experiences a brief decrease from $0.5 \mathrm{~mm} /$ day to $5 \mathrm{~mm}$ /day and then begins to climb up from there. The relative standard deviation in JJA can reach nearly $18 \%$ at the rain rate of $35 \mathrm{~mm} /$ day. From Figure 1, it is seen that regions of high rain rates in JJA are confined mainly in orographically influenced regions such as the windward side of southwest India. In short, all three products do not quite agree with each other (between $\sim 7 \%$ and $\sim 13 \%$ of the ensemble mean) and even more so in JJA than in the other three seasons. Larger variations are found in JJA and they increase with rain rates. Relatively smaller variations are found in SON, DJF and MAM.

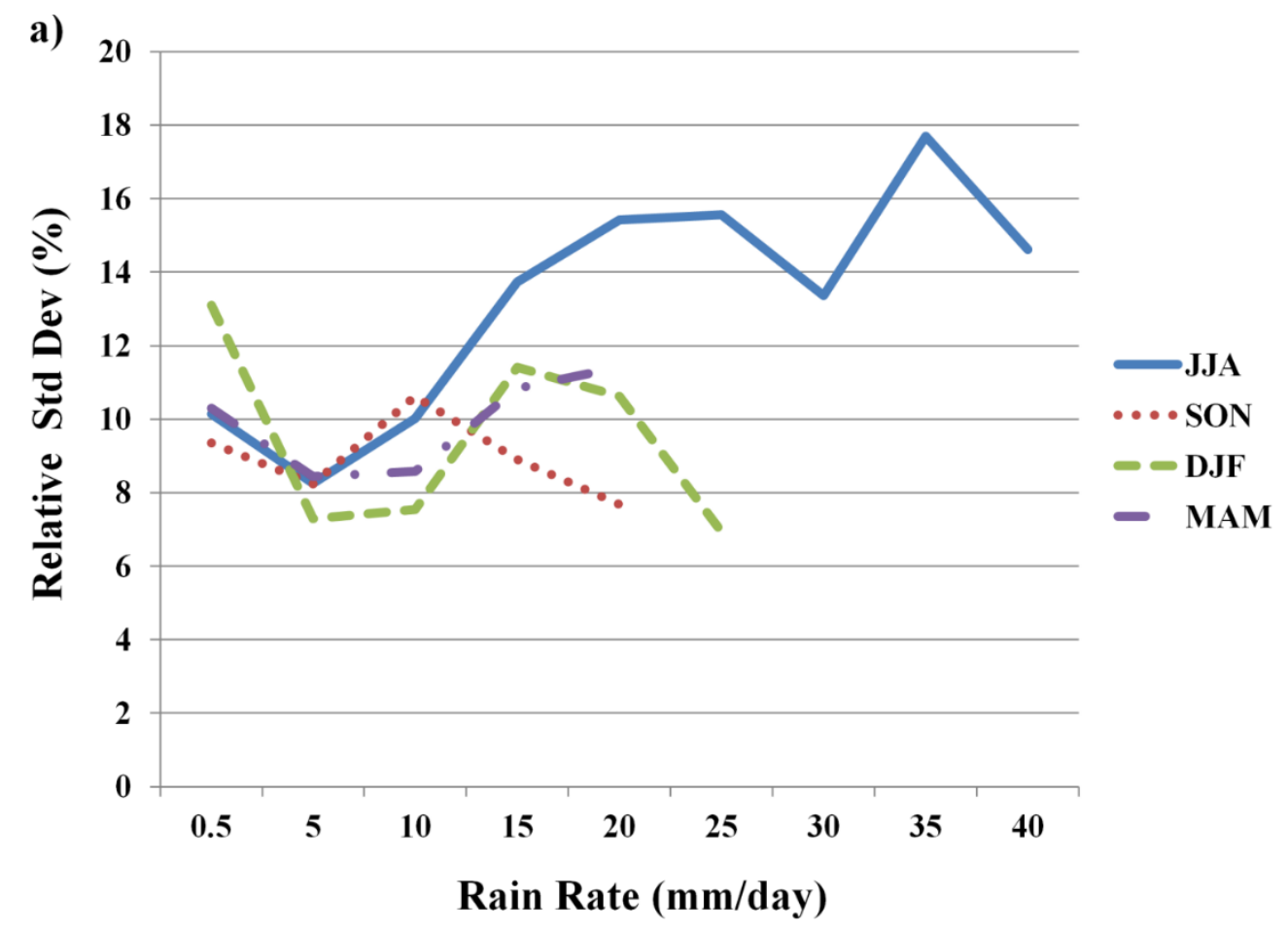

Figure 3. Cont. 
b)

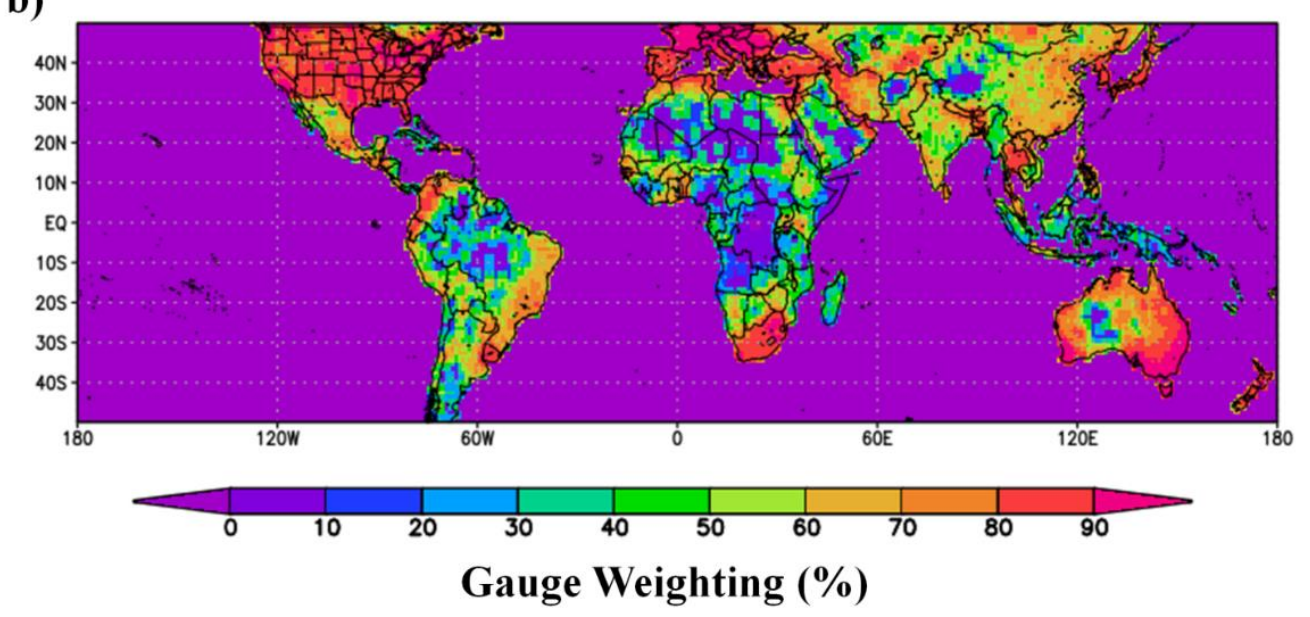

Figure 3. (a) Relative (with respect to the ensemble mean) standard deviation in percentages (\%) as a function of rain rate. (b) Gauge weighting in percentage averaged between 1998 and 2013.

Rain gauge data are used in the bias correction in the 3B43 algorithm [9-12]. Figure 3b shows a map of the gauge weighting percentages averaged between 1998 and 2013. It is seen gauge weighting percentages are not evenly distributed around the world, with higher percentages in developed countries and populated regions where more gauge data are available, such as North America, Europe, etc. than those in developing countries and less populated/remote regions (the Sahara Desert, the Amazon basin). The lack of gauge data in deserts is likely to be one of the contributing factors in the large standard deviations mentioned earlier in addition to the difficulty of observing light rain events from satellite-based sensors. More on this will be found in the discussion section.

To examine whether these three climatologies share the similar seasonal variations, Pearson's correlation coefficients were computed from January to December (12 months). Figure 4 shows the maps of Pearson's correlation coefficients for each pair of climatology. In general, high correlation coefficients $(>0.9)$ are found in most regions in all three pairs (Figure 4). However, significantly low positive $(<0.7)$ or even low negative correlation coefficients are found in regions of light rain $(<0.5 \mathrm{~mm} /$ day $)$ such as the Sahara Desert, the Arabian Peninsula, Southern Australia, the Andes, the Southwestern United Sates, etc. As indicated earlier, large variations and uncertainty in light rain regions as well as other factors to be discussed later can be the main reasons for the observed low correlation coefficients in those regions. The two gauge-based climatologies are more closely related than 3B43 and the two gauge climatologies (Figure 4), respectively. In summary, the 3B43 climatology can adequately catch the seasonal variations in many regions around the world except for the light rain regions where even the two gauge climatologies do not quite agree.

Zonal means can be another indicator for assessing whether 3B43 can successfully catch the meridional distribution of precipitation in all seasons. Figure 5 contains the zonal means from the three climatologies for each season. It is seen that the 3B43 climatology can successfully reproduce the meridional distribution of precipitation and catch the seasonal shifts of the heavy rain band in the Tropics (Figure 5). Three zonal means in Figure 5 are quite similar with very little differences in rain rates in all seasons between $40^{\circ} \mathrm{N}$ and $40^{\circ} \mathrm{S}$; however, it is seen that rain rates from WM are in general slightly lower than GPCC in some latitudes in particular in JJA and SON (Figure 5). Likewise, 3B43 rain rates 
are higher than the other two, especially in DJF. The bias issue associated with rain rates will be further discussed in the next section. Outside this belt, the differences in the three climatologies are more visible and 3B43 rain rates are higher than the rest especially in DJF and MAM; however, the rain rates there in general are much smaller than those in the tropical and sub-tropical regions. These differences appear to be related to precipitation types such as mixed or frozen precipitation. To conclude, 3B43 performs considerably well between $40^{\circ} \mathrm{N}$ and $40^{\circ} \mathrm{S}$.

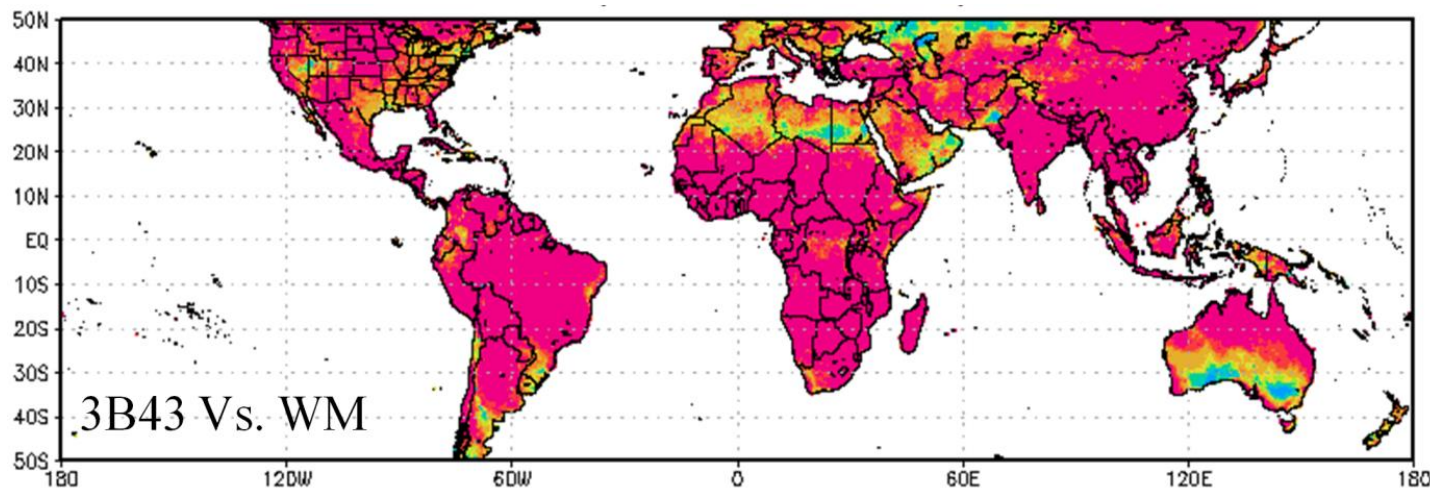

(a)

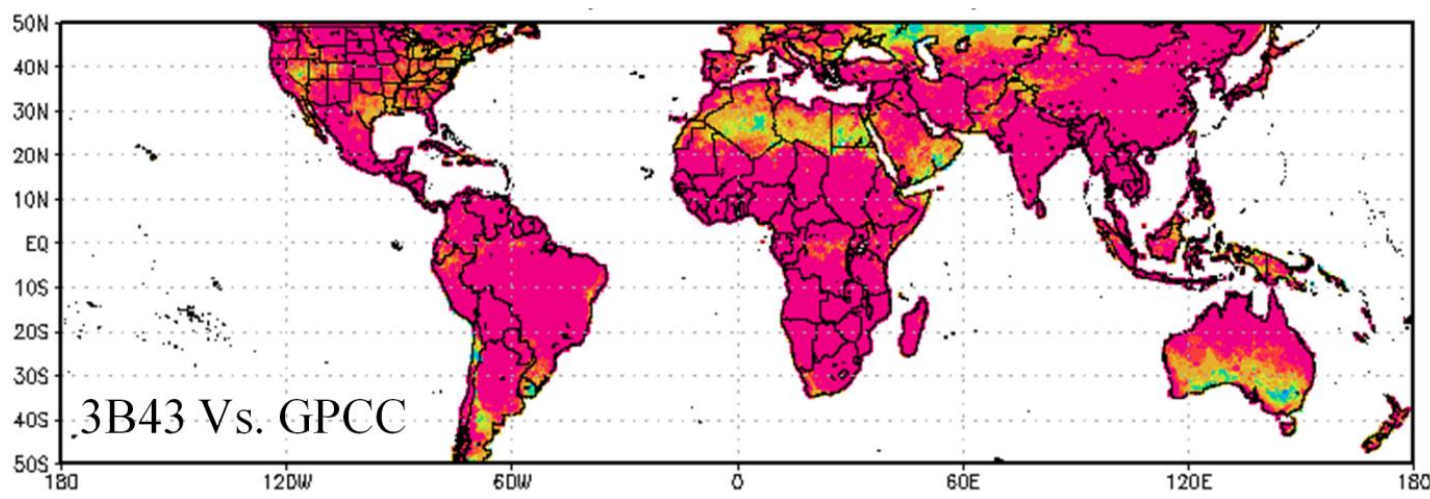

(b)
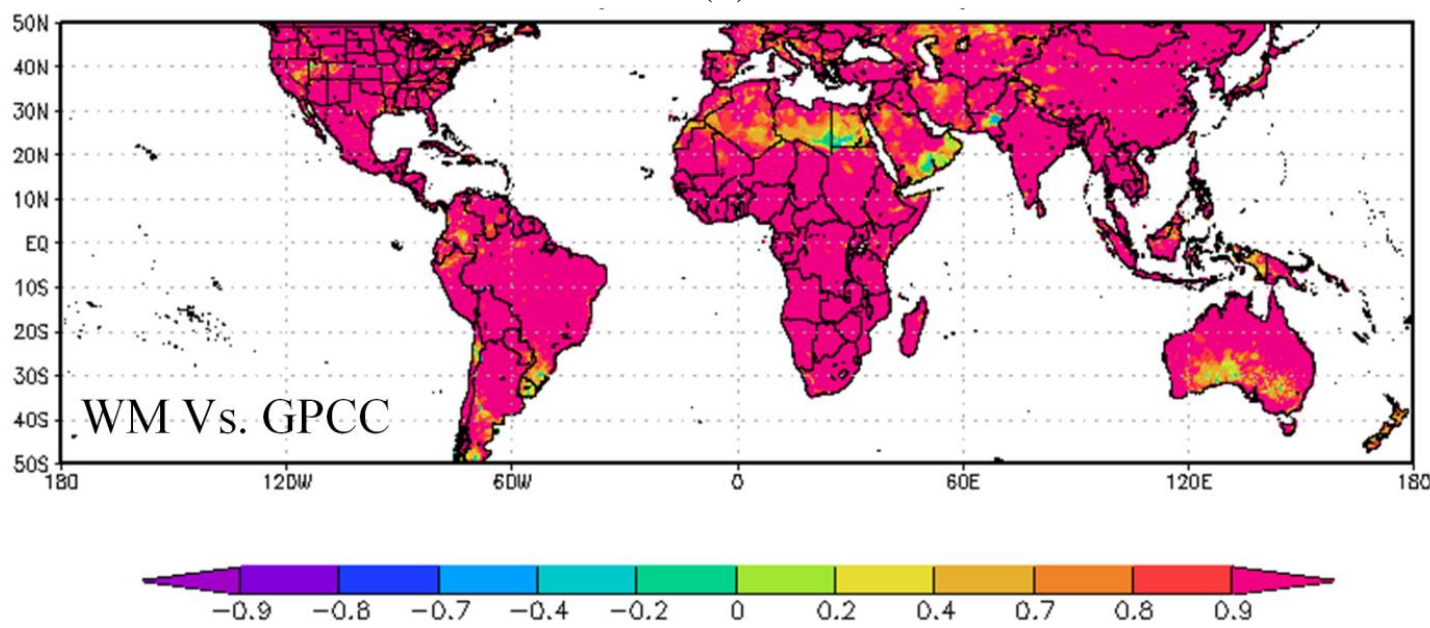

(c)

Figure 4. Pearson's correlation coefficients between (a) 3B43 and WM; (b) 3B43 and GPCC; and (c) WM and GPCC. 
a)

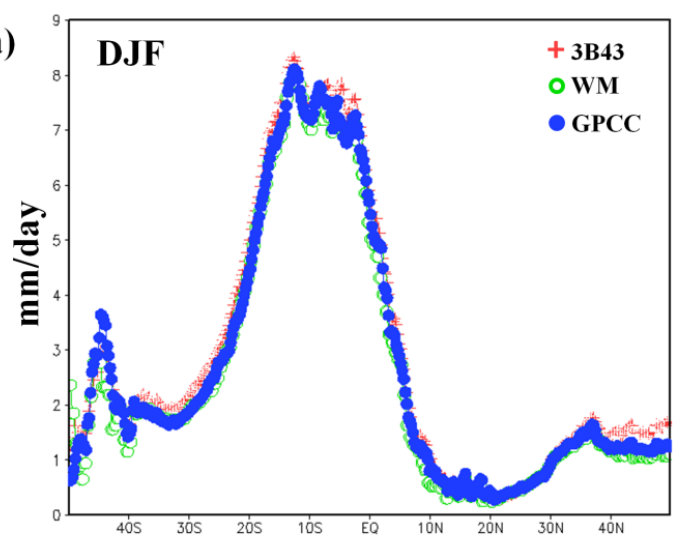

c)

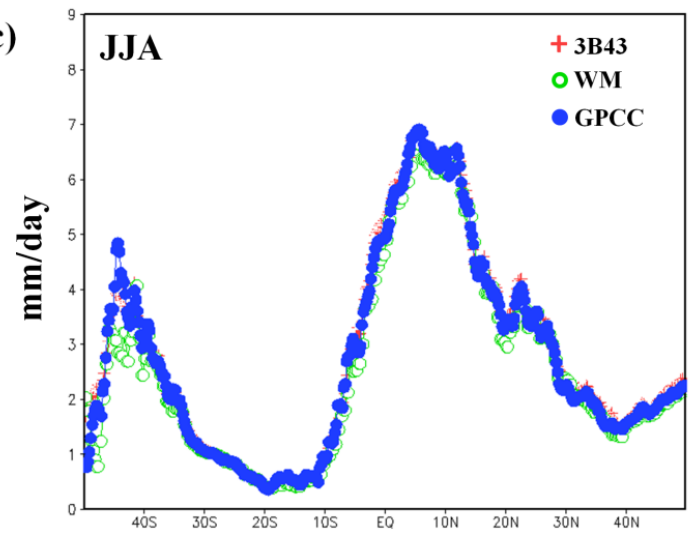

b)

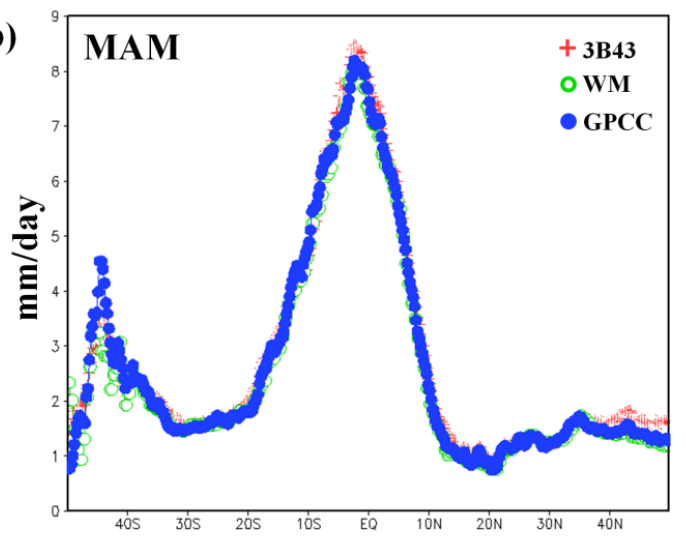

d)

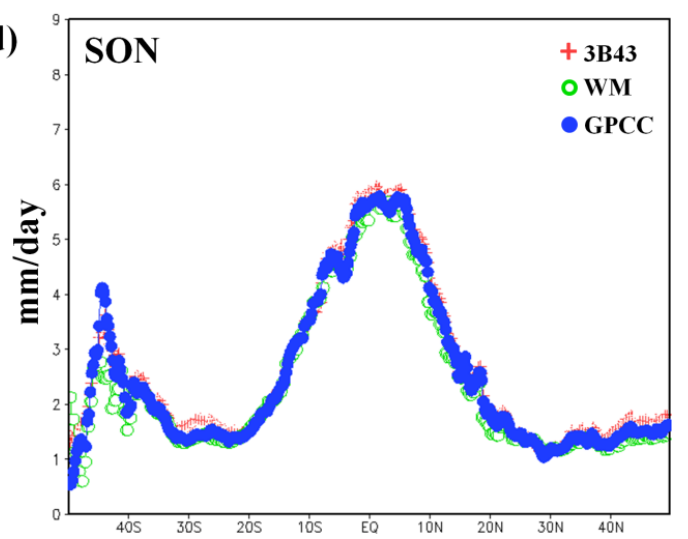

Figure 5. Zone means of 3B43, WM and GPCC for (a) DJF; (b) MAM; (c) JJA; and (d) SON.

\subsection{Bias Assessment}

Figure 6 contains scatterplots between the three climatology pairs in four seasons. Higher rain rates (Figure 6c,g,k) are found in JJA, as shown earlier. In JJA, points spread wider than in other seasons (Figure 6). In addition, more points in high rain rates are found above the 1:1 line in both 3B43 vs. WM (Figure 6c) and 3B43 vs. GPCC (Figure 6g), suggesting large negative biases (3B43 < WM and 3B43 < GPCC) at high rain rates. Such large biases are only found in JJA and biases in other seasons are relatively small. Compared to the other two pairs, the biases are smaller between GPCC and WM (Figure 6k); however the points (Figure 6k) spread similarly to the other two pairs (Figure 6c,g) along the 1:1 line, suggesting that significant differences exist in the two gauge-based climatologies as well.

Figure 6 only shows that biases exist among the three climatology pairs. Figure 7 shows the quantified biases among 3B43, WM and GPCC at different rain rates in four seasons. For all seasons, both 3B43 vs. WM (Figure 7a) and 3B43 vs. GPCC (Figure 7b) pairs all show positive biases (i.e., 3B43 > WM) at low rain rates and negative biases at high rain rates. The latter confirms the findings in Figure 6. In JJA when the rain rates are the highest in all seasons, it is seen that the negative bias between 3B43 and WM can reach near $-20 \%$ of the mean at the highest rain rate (Figure $7 \mathrm{a})$. A much larger $(\sim-36 \%)$ bias can be found in the 3B43 vs. GPCC pair (Figure 7b), which is much larger than that between 3B43 and WM. The differences between WM and GPCC (Figure 7c) are smaller than the other two pairs. 

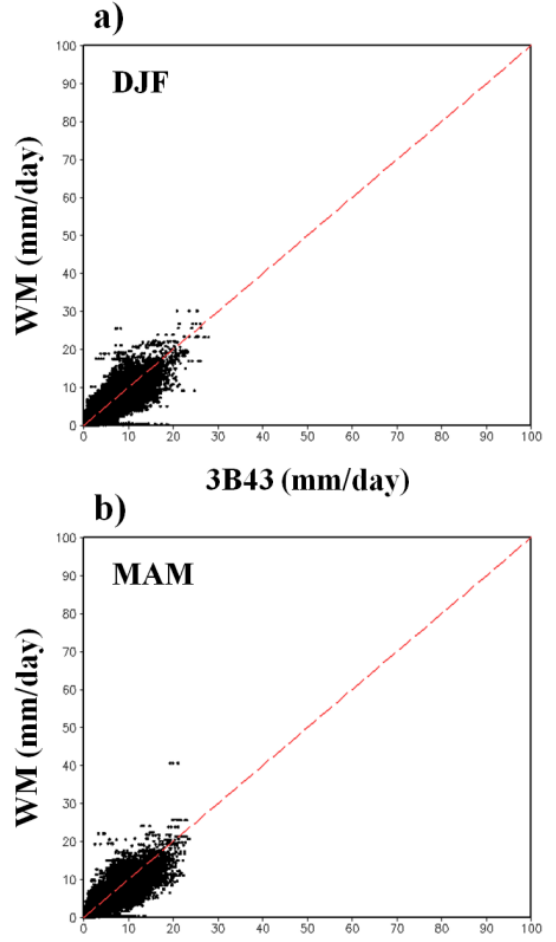

$3 B 43(\mathrm{~mm} / \mathrm{day})$

c)

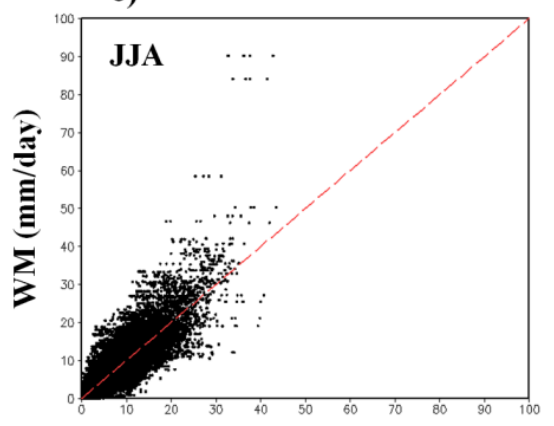

d)

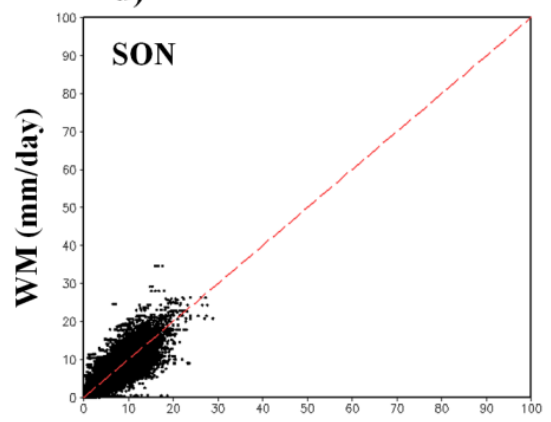

3 B43 (mm/day) e)

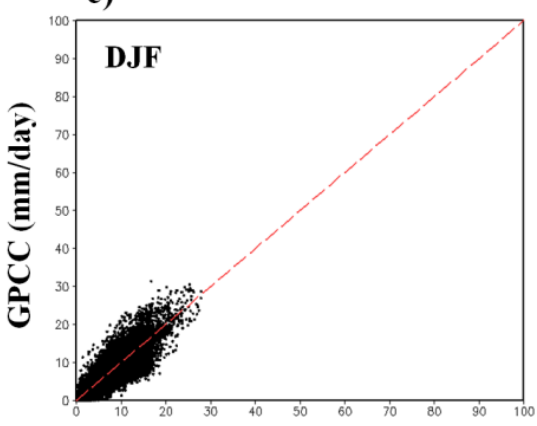

$3 B 43$ (mm/day)

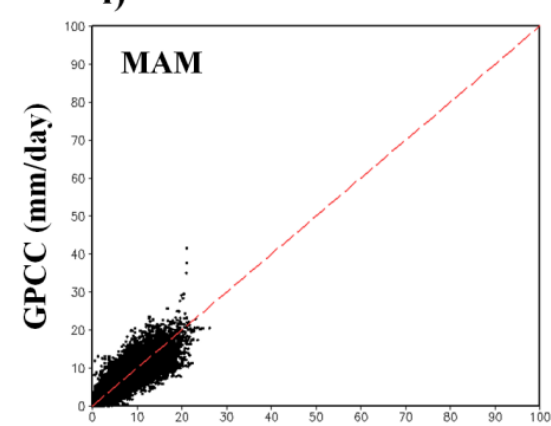

$3 B 43(\mathrm{~mm} / \mathrm{day})$

g)

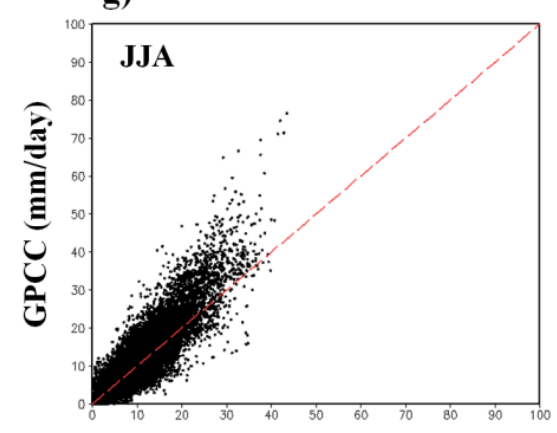

$3 B 43$ (mm/day) h)

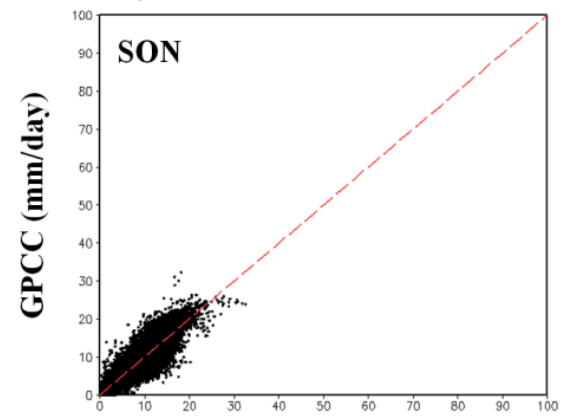

$3 B 43$ (mm/day)

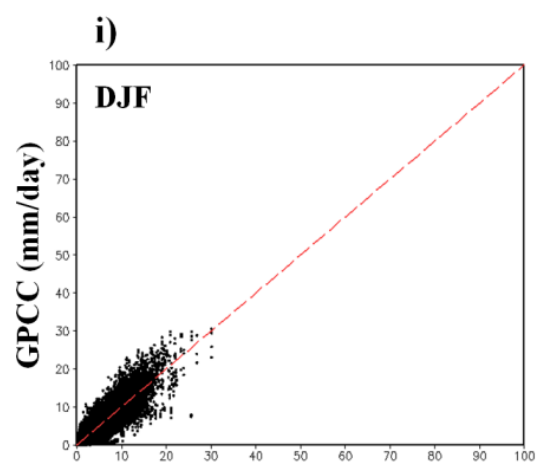

WM (mm/day)

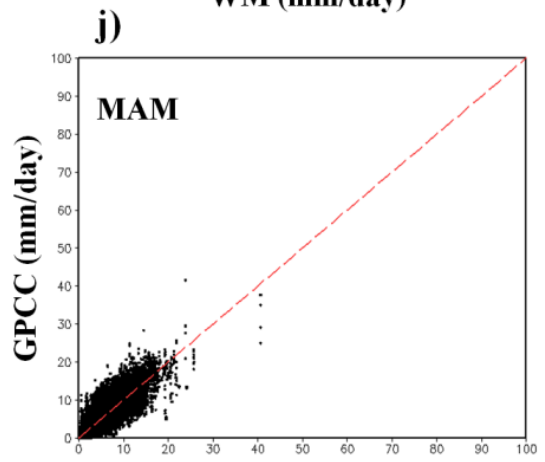

WM (mm/day)

k)

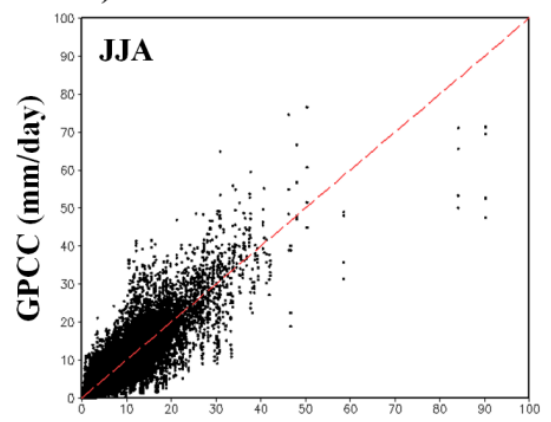

WM (mm/day)

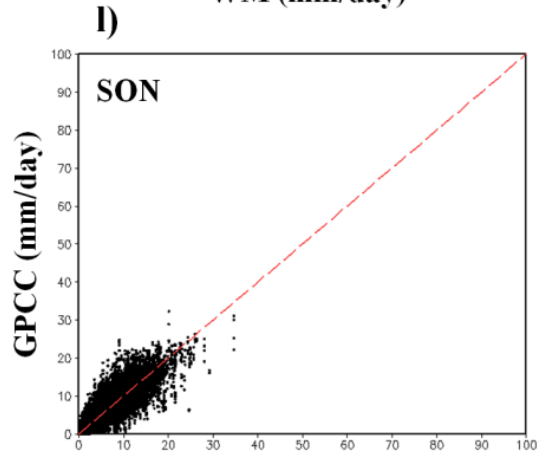

WM (mm/day)

Figure 6. Scatterplots between: WM and 3B43 for (a) DJF; (b) MAM; (c) JJA; and (d) SON; GPCC and 3B43 for (e) DJF; (f) MAM; (g) JJA; and (h) SON; and GPCC and WM for (i) DJF; (j) MAM; (k) JJA; and (l) SON. Each black dot represents the rain rate of a grid point in each dataset. The red dashed line is the 1:1 line. 
a)

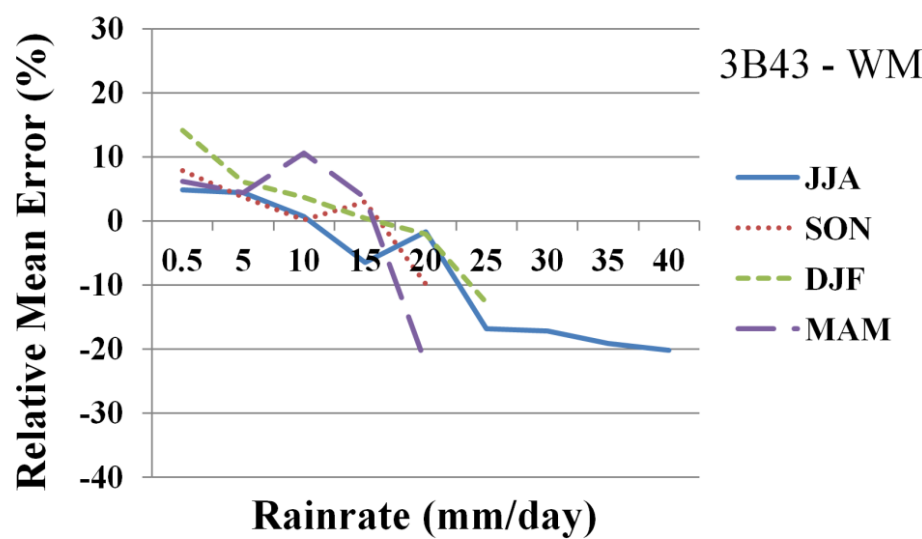

b)

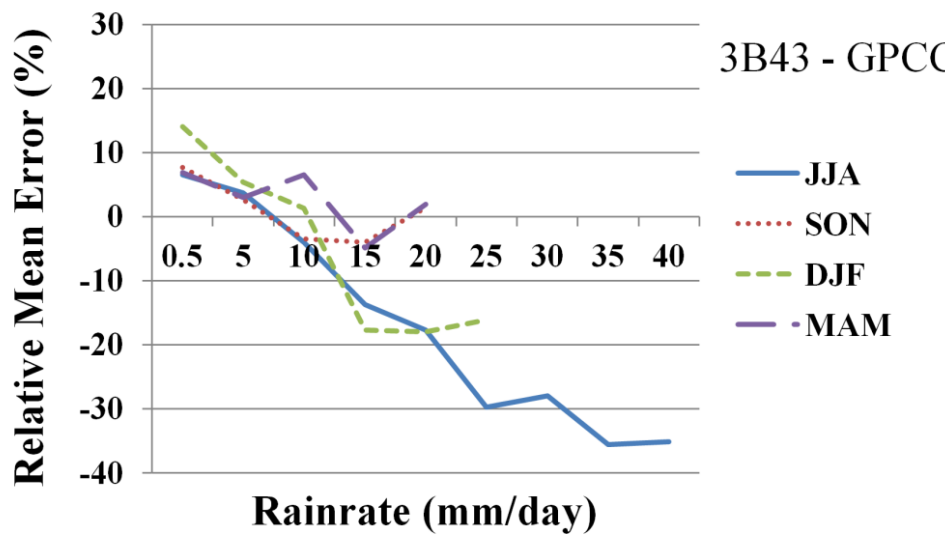

c)

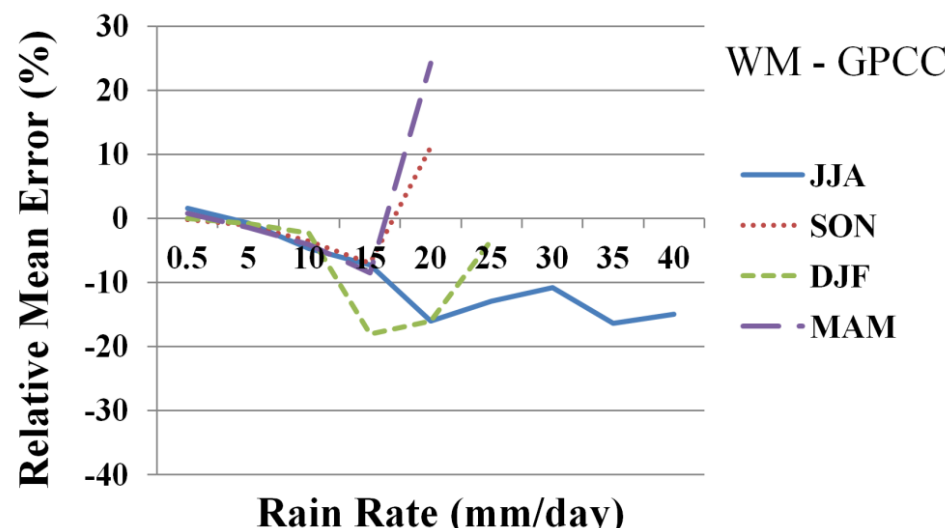

Figure 7. Relative (with respect to the mean) mean error between: (a) 3B43 and WM; (b) 3B43 and GPCC; and (c) WM and GPCC.

In MAM, large biases at high rain rates are found between 3B43 and WM (Figure 7a) as well as between WM and GPCC at $20 \mathrm{~mm} /$ day (Figure 7c), which is not found in those between 3B43 and GPCC (Figure $7 \mathrm{~b}$ ). In contrast, large biases at high rain rates between $3 \mathrm{~B} 43$ and GPCC at $15 \mathrm{~mm} /$ day and above (Figure 7b) and between WM and GPCC at $15 \mathrm{~mm} /$ day and $20 \mathrm{~mm} /$ day are found in DJF (Figure 7c), but not found between 3B43 and WM (Figure 7a). The biases between the WM vs. GPCC pair (Figure 7c) are, in general, smaller than the other two pairs, as shown in the scatterplot in Figure 6, but for some reason, the differences at $20 \mathrm{~mm} /$ day are larger than the other two pairs. Negative systematic differences (Figure 7c) prevail in all seasons, except in MAM and SON at $20 \mathrm{~mm} / \mathrm{day}$. Nonetheless, 3B43 biases vary with rain rates with positive biases at low rain rates and much larger negative biases at high rain rates, especially in JJA, MAM and DJF. 
To better understand the high biases at high rain rates in JJA shown in Figure $6 \mathrm{c}, \mathrm{g}, \mathrm{k}$, it is necessary to examine regions of high rain rates and the spatial distribution of bias. Figure 8a shows the regional 3B43 rain rate climatology for JJA in Southeast Asia and India where high rain rates are located. In Figure $8 \mathrm{a}$, it is seen that the regions of high rain rates are found in orographically influenced regions such as the Western Ghats of India, the coasts of Thailand and Burma (Myanmar). As mentioned earlier, these regions are heavily influenced by the orographic uplifting effect [29], characterized with high/low rain rates along the coastal windward/leeward sides of the mountains. The relative (with respect to the mean in Figure 8a) difference map (Figure 8b) between 3B43 and GPCC shows that the biases are not evenly distributed: large negative biases $(3 \mathrm{~B} 43<\mathrm{GPCC})$ are found in high rain rate regions along the coastal windward sides (Figure $8 \mathrm{~b}$ ). In contrast, large positive biases are found in the light rain rate regions such as the leeward side of the Western Ghats (Figure 8b).

a)
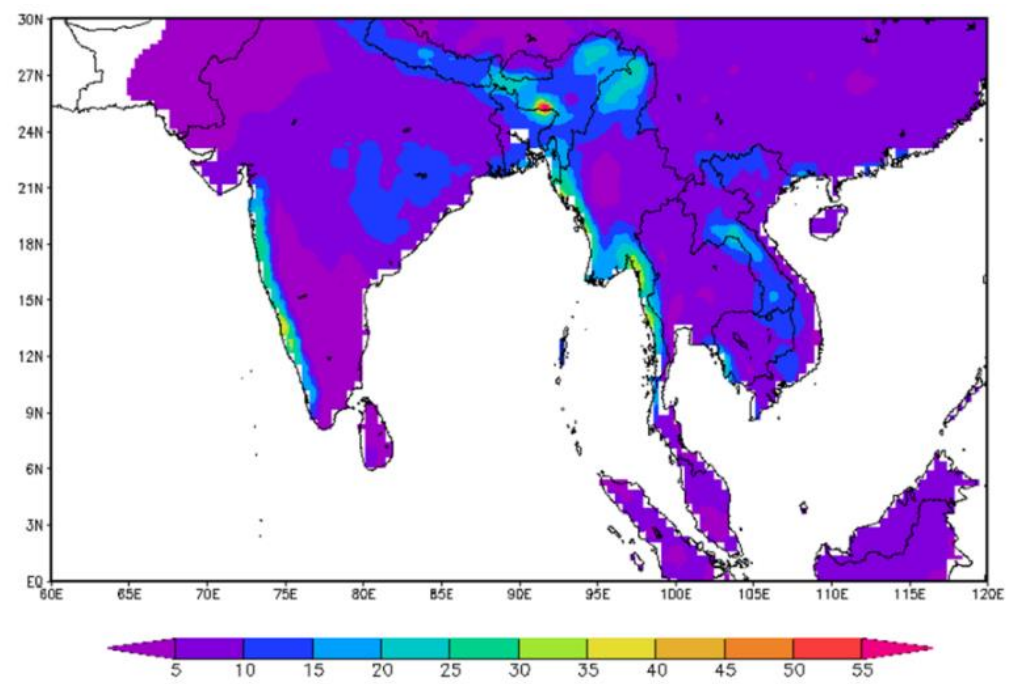

3B43 Rainfall Climatology for JJA ( $\mathrm{mm} / \mathrm{day})$

b)

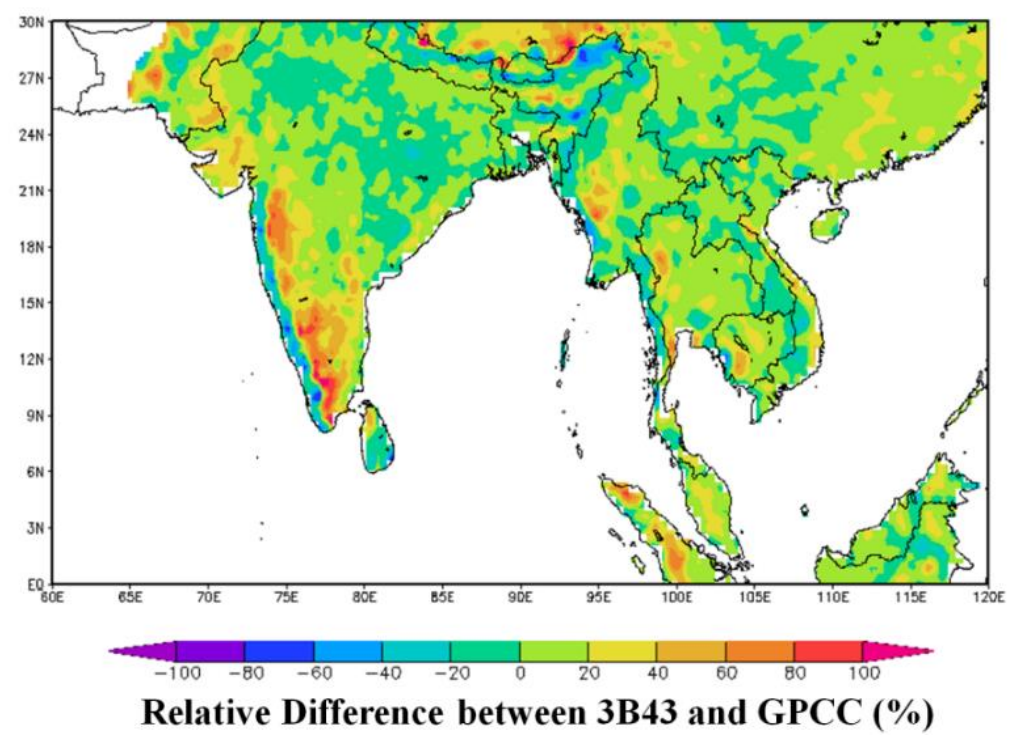

Figure 8. Cont. 


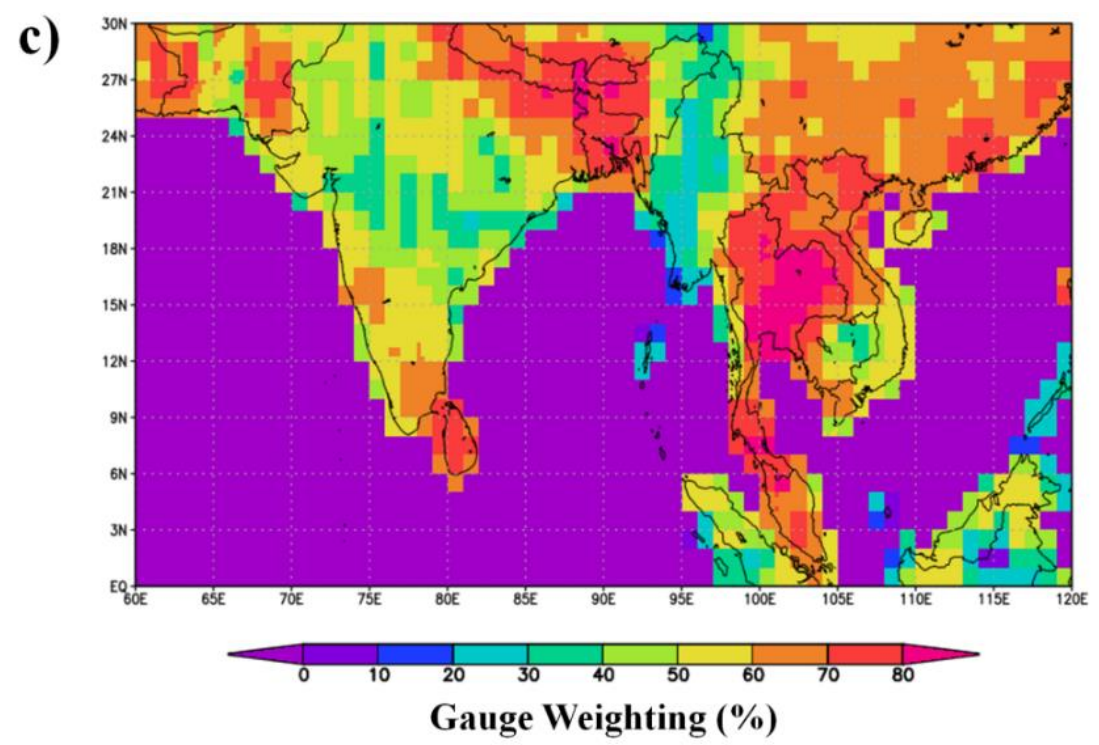

Figure 8. (a) 3B43 rainfall climatology in mm/day for JJA; (b) Relative (with respect to the mean in (a)) rain rate difference between 3B43 and GPCC in percentages; (c) Gauge weighting (in percentages) averaged between 1998 and 2013 for JJA.

Gauge data are an important data source for bias correction in satellite-based precipitation products such as 3B43 [9-12]. Therefore, the availability of gauge data can have a significant impact on data quality. Numerous validation studies show that data quality can be linked closely to the availability of gauge data in a study area. Figure 8c is a map of gauge weighting in percentage averaged between 1998 and 2013 for JJA. High percentages suggest that more gauge data are available for bias correction in the algorithm. It is seen that the weighting percentages along the coastal windward sides are in general not very high, especially in Burma where the percentages range only between 10\%-30\%. In short, the availability of gauge data can vary greatly (Figure 8c), which needs to be considered when assessing data quality of 3B43. Meanwhile, density of a gauge network can also influence the quality of a gauge-based precipitation product.

\section{Summary and Discussion}

A satellite-based precipitation climatology, derived from the popular TMPA monthly product (3B43), was evaluated over land on a near-global scale with two gauge-based products (GPCC and WM). Statistical results show that the 3B43 climatology, in general, performs well against the two gauge-based climatologies, namely, all three products are quite similar and their variations are less than $\sim 15 \%$ of the means. However, the variations are not evenly distributed around the world. When rain rates are lighter than $0.5 \mathrm{~mm} /$ day in remote and less populated regions such as the Sahara Desert, the Arabian Peninsula, the Tibetan Plateau, the Andes, etc. large variations in rain rates are found, suggesting that large uncertainties exist, including the two gauge-based climatologies as well. It is worth noting that light rain rate here does not mean light rain events in those regions. For example, studies (i.e., [30]) show that Saharan rainfall can be highly irregular and can be heavy during a MCS (mesoscale convective system) event and as a result, light rain appears in the climatology after a long time period (for 3B43, 16 years) of averaging. Seasonal analysis shows that the largest variation $(\sim 18 \%)$ is found at $35 \mathrm{~mm} /$ day in JJA 
and the variations for other seasons range between $\sim 7 \%$ and $\sim 13 \%$ of the ensemble means at different rain rates.

Seasonal variations were compared using Pearson's correlation coefficients. Results show that high correlation coefficients ( $>0.9)$ are found in most regions except in the light rain $(<0.5 \mathrm{~mm} /$ day $)$ regions where large variations in rain rates are found as well. Nonetheless, the $3 \mathrm{~B} 43$ climatology can correctly catch the seasonal variations in many regions, except the light rain regions.

The meridional distribution of precipitation was examined by computing the zonal means of the three climatologies in four seasons. Overall, 3B43 performs very well by reproducing the meridional distribution of precipitation with small differences between $40^{\circ} \mathrm{N}-40^{\circ} \mathrm{S}$. The differences are more noticeable predominantly in cold seasons outside the $40^{\circ} \mathrm{N}-40^{\circ} \mathrm{S}$ belt where light and mixed precipitation prevails.

Finally, biases between 3B43 and the two gauge-based products were investigated. Basically, the biases between the two gauge-based climatologies are in general smaller than 3B43 vs. WM and 3B43 vs. GPCC, respectively. However, differences do exist in these two gauge-based datasets. In JJA, precipitation estimates are more spread out along the 1:1 line than in the other seasons. At high rain rates, 3B43 has low biases against GPCC and WM. The biases are not consistent, with positive biases $(3 \mathrm{~B} 43>\mathrm{WM}$ and 3B43 > GPCC) found at low rain rates and much larger negative biases $(3 \mathrm{~B} 43<\mathrm{WM}$ and 3B43 < GPCC) at high rain rates, especially in JJA. The negative biases can be as high as $20 \%$ of the ensemble means for WM and 36\% for GPCC; however, the regions with such high rain rates are confined in orographically influenced regions such as along the windward coasts. This orographically associated issue has been discussed by several investigators [12,31-33] and their results show that shallow orographic rain rates are underestimated in microwave radiometer algorithms due to weak ice scattering signatures [31] as well as the lack of gauge data for bias correction. As a result, new methods have been developed to correct the said issue [12,31-33].

As mentioned earlier, many verification and validation activities have been done at local and regional scales with dense rain gauge networks. For example, Prakash et al. [34] and Kim et al. [35] have conducted seasonal intercomparison analysis with gridded rain gauge data from the India Meteorological Department (IMD) due to its high gauge density. Several precipitation products were compared including the GPCC product. Their results show that most precipitation products had difficulties in representing rainfall over orographic regions including the Western Ghats mountains, Northeast India and the Himalayan foothills, implying that even gauge-based products like the GPCC may still have serious issues. Joss and Lee [36] discussed gauge network density issues in precipitation product validation in complex terrain and they found a large number of gauges are needed in order to correctly depict a rain event.

In addition to the orographic factor, other factors need to be considered as well, such as deficiencies in space as in rain gauge measurement which cause issues in measuring convective rain which is highly inhomogeneous as well as measuring rainfall during high wind conditions.

Wang et al., (2014) compared TCC (mainly 3B43, mentioned earlier) with GPCC over land in southeastern China and southeastern United States, respectively. They found that, in general, TCC estimates are smaller than GPCC, especially at high rain rates, which is consistent with the results in this study. However, TCC behaves a little bit differently in the two regions. In southeastern China, negative biases (TCC < GPCC) prevail; in contrast, the negative biases are not that obvious with positive biases 
at low rain rates in southeastern United States. As seen earlier, spatial variations in bias do exist; therefore, a separate investigation is needed for a different area of interest to ensure that more accurate biases can be analyzed.

As mentioned in Section 2, the 3B43 algorithm includes the monthly gauge analysis using inverse-error-variance weighting. From the GPCC product information page [37], the GPCC monitoring product that is used in the 3B43 algorithm for bias correction contains quality-controlled gauge data from 7000-8000 stations. By contract, the GPCC product used in this study contains much more quality-controlled gauge data from 67,200 stations. The difference in ground observation stations may explain the previously mentioned difference between 3B43 and GPCC, because more gauge data can increase gauge weighting percentages and biases can be corrected more adequately. Nonetheless, it is a challenge to conduct bias correction under the condition of limited gauges. As mentioned earlier, another way to combat this issue is to continue improving the algorithm, making it less relying on gauge-based bias correction.

Estimates for light rain still remain a challenge not only for satellite-based algorithms [10,28], but also for gauge-based measurements, as seen in this study. Although the problematic regions are remote and less populated, in order to better understand the global climate, it is necessary to be able to obtain correct information no matter what rain rate it may be for any missing or incorrect information can create difficulties in understanding the global hydrological cycle. This similar situation may apply to oceans as well where there has been no gauge-based bias correction so far.

\section{Acknowledgments}

This project is supported by NASA Research Opportunities in Space and Earth Science-2010 (ROSES-2010), NNH10ZDA001N-ESDRERR, Appendix A.32: "Earth System Data Records Uncertainty Analysis". Special thanks to the GES DISC and the Giovanni development team. The TMPA data were provided by the NASA Goddard Space Flight Center's Mesoscale Atmospheric Processes Laboratory and Precipitation Processing System (PPS), which develop and compute the TMPA as a contribution to TRMM. The author would like to thank two anonymous reviewers for their thought-provoking and constructive comments.

\section{Conflicts of Interest}

The authors declare no conflict of interest.

\section{References}

1. Liu, Z. Comparison of global precipitation climatology products derived from ground and satellite-based measurements. Proc. SPIE 2014, doi:10.1117/12.2066910.

2. Houze, R.A.; Rasmussen, K.L.; Medina, S.; Brodzik, S.R.; Romatschke, U. Anomalous atmospheric events leading to the summer 2010 floods in Pakistan. Bull. Am. Meteorol. Soc. 2011, 92, 291-298.

3. Tripoli, G.J.; Medaglia, C.M.; Dietrich, S.; Mugnai, A.; Panegrossi, G.; Pinori, S.; Smith, E.A. The 9-10 November 2001 Algerian Flood: A numerical study. Bull. Am. Meteorol. Soc. 2005, 86, $1229-1235$. 
4. Hoerling, M.; Kumar, A.; Dole, R.; Nielsen-Gammon, J.; Eischeid, J.; Perlwitz, J.; Quan, X.; Zhang, T.; Pegion, P.; Chen, M. Anatomy of an extreme event. J. Clim. 2013, 26, 2811-2832.

5. Garstang, M.; Kummerow, C.D. The Joanne Simpson special issue on the tropical rainfall measuring mission (TRMM). J. Appl. Meteorol. 2000, 39, 1961.

6. Liu, Z.; Ostrenga, D.; Teng, W.; Kempler, S. Tropical rainfall measuring mission (TRMM) precipitation data and services for research and applications. Bull. Am. Meteorol. Soc. 2012, 93, 1317-1325.

7. Adler, R.F.; Wang, J.-J.; Gu, G.; Huffman, G.J. A ten-year tropical rainfall climatology based on a composite of TRMM products. J. Meteorol. Soc. Jpn. 2009, 87, 281-293.

8. Wang, J.-J.; Adler, R.F.; Huffman, G.J.; Bolvin, D. An updated TRMM composite climatology of tropical rainfall and its validation. J. Clim. 2014, 27, 273-284.

9. Huffman, G.J. Estimates of root-mean-square random error for finite samples of estimated precipitation. J. Appl. Meteorol. 1997, 1191-1201.

10. Huffman, G.J.; Adler, R.F.; Bolvin, D.T.; Gu, G.; Nelkin, E.J.; Bowman, K.P.; Hong, Y.; Stocker, E.F.; Wolff, D.B. The TRMM multi-satellite precipitation analysis: Quasi-Global, multi-year, combined-sensor precipitation estimates at fine scale. J. Hydrometeorol. 2007, 8, 38-55.

11. Huffman, G.J.; Adler, R.F.; Bolvin, D.T.; Nelkin, E.J. The TRMM multi-satellite precipitation analysis (TMPA). In Satellite Rainfall Applications for Surface Hydrology; Hossain, F., Gebremichael, M., Eds.; Springer Verlag: Berlin, Germany, 2010; pp. 3-22.

12. Huffman, G.J.; Bolvin, D.T. TRMM and Other Data Precipitation Data Set Documentation. Available online: ftp://meso-a.gsfc.nasa.gov/pub/trmmdocs/3B42_3B43_doc.pdf (accessed on 5 August 2015).

13. Liu, Z.; Ostrenga, D.; Teng, W.; Kempler, S.; Milich, L. Developing GIOVANNI-based online prototypes to intercompare TRMM-related global gridded-precipitation products. Comput. Geosci. 2014, 66, 168-181.

14. Mirador. Available online: http://mirador.gsfc.nasa.gov (accessed on 5 August 2015).

15. Willmott, C.J.; Matsuura, K. Terrestrial Air Temperature and Precipitation: Monthly and Annual Time Series (1950-1999). Available online: http://climate.geog.udel.edu/ climate/html_pages/ README.ghen_ts2.html (accessed on 5 August 2015).

16. Legates, D.R.; Willmott, C.J. Mean seasonal and spatial variability global surface air temperature. Theor. Appl. Climatol. 1990, 41, 11-21.

17. Legates, D.R.; Willmott, C.J. Mean seasonal and spatial variability in gauge-corrected, global precipitation. Int. J. Climatol. 1990, 10, 111-127.

18. Willmott, C.J.; Matsuura, K.; Legates, D.R. Global Air Temperature and Precipitation: Regridded Monthly and Annual Climatologies. Available online: http://climate.geog.udel.edu/ climate (accessed on 5 August2015).

19. Shepard, D. A two-dimensional Interpolation function for irregularly-spaced data. In Proceedings of the 1968 ACM National Conference, Las Vegas, NV, USA, 27-29 August 1968; pp. 517-524. Available online: http://dl.acm.org/citation.cfm?id=810616 (accessed on 5 August 2015).

20. Willmott, C.J.; Rowe, C.M.; Philpot, W.D. Small-scale climate maps: A sensitivity analysis of some common assumptions associated with grid-point interpolation and contouring. Am. Cartogr. 1985, $12,5-16$. 
21. Meyer-Christoffer, A.; Becker, A.; Finger, P.; Rudolf, B.; Schneider, U.; Ziese, M. GPCC Climatology Version 2011 at $0.25^{\circ}$ : Monthly Land-Surface Precipitation Climatology for Every Month and the Total Year from Rain-Gauges Built on GTS-Based and Historic Data. Available online: ftp://ftp.dwd.de/pub/data/gpcc/html/gpcc_normals_v2011_doi_download.html (accessed on 5 August 2015).

22. Giovanni TOVAS. Available online: http://gdata1.sci.gsfc.nasa.gov/daac-bin/G3/gui.cgi? instance_id=TRMM_Clim (accessed on 5 August 2015).

23. Liu, Z.; Rui, H.; Teng, W.; Chiu, L.; Leptoukh, G.; Vicente, G. Online visualization and analysis: A new avenue to use satellite data for weather, climate and interdisciplinary research and applications. Measuring precipitation from space-EURAINSAT and the future. Adv. Glob. Change Res. 2007, 28, 549-558.

24. Liu, Z.; Rui, H.; Teng, W.; Chiu, L.S.; Leptoukh, G.G.; Kempler, S. Developing an online information system prototype for global satellite precipitation algorithm validation and intercomparison. J. Appl. Meteorol. Climatol. 2009, 48, 2581-2589.

25. Giovanni. Available online: http://giovanni.gsfc.nasa.gov (accessed on 5 August 2015).

26. Acker, J.G.; Leptoukh, G. Online analysis enhances use of NASA earth science data. Eos Trans. Am. Geophys. Union 2007, 88, 14-17.

27. Berrick, S.W.; Leptoukh, G.; Farley, J.D.; Rui, H. Giovanni: A Web service workflow-based data visualization and analysis system. IEEE Trans. Geosci. Remote Sens. 2009, 47, 106-113.

28. Tian, Y.; Peters-Lidard, C.D. A global map of uncertainties in satellite-based precipitation measurements. Geophys. Res. Lett. 2010, 37, L24407.

29. Whiteman, D. Mountain Meteorology: Fundamentals and Applications; Oxford University Press: Oxford, UK, 2000; p. 355.

30. Kelley, O.A. Where the least rainfall occurs in the Sahara Desert, the TRMM radar reveals a different pattern of rainfall each season. J. Climate 2014, 27, 6919-6939.

31. Shige, S.; Kida, S.; Ashiwake, H.; Kubota, T.; Aonashi, K. Improvement of TMI rain retrievals in mountainous areas. J. Appl. Meteorol. Climatol. 2013, 52, 242-254.

32. Shige, S.; Yamamoto, M.K.; Taniguchi, A. Improvement of TMI rain retrieval over the Indian Subcontinent. In Remote Sensing of the Terrestrial Water Cycle; Lakshmi, V., Alsdorf, D., Anderson, M., Biancamaria, S., Cosh, M., Entin, J., Huffman, G., Kustas, W., van Oevelen, P., Painter, T., et al., Eds.; John Wiley \& Sons, Inc.: Hoboken, NJ, USA, 2014; pp. 27-42.

33. Yamamoto, M.K.; Shige, S. Implementation of an orographic/nonorographic rainfall classification scheme in the GSMaP algorithm for microwave radiometers. Atmos. Res. 2014, doi:10.1016/j.atmosres.2014.07.024.

34. Prakash, S.; Mitra, A.K.; Momin, I.M.; Rajagopal, E.N.; Basu, S.; Collins, M.; Turner, A.G.; Achuta Rao, K.; Ashok, K. Seasonal intercomparison of observational rainfall datasets over India during the southwest monsoon season. Int. J. Climatol. 2015, 35, 2326-2338.

35. Kim, J.; Sanjay, J.; Mattmann, C.; Boustani, M.; Ramarao, M.V.S.; Krishnan, R.; Waliser, D. Uncertainties in estimating spatial and interannual variations in precipitation climatology in the India-Tibet region from multiple gridded precipitation datasets. Int. J. Climatol. 2015, doi:10.1002/joc. 4306 . 
36. Joss, J.; Lee, R. The application of radar-gauge comparisons to operational precipitation profile corrections. J. Appl. Meteorol. 1995, 34, 2612-2630.

37. GPCC Product Information Page. Available online: http://gpcc.dwd.de (accessed on 5 August 2015).

(C) 2015 by the author; licensee MDPI, Basel, Switzerland. This article is an open access article distributed under the terms and conditions of the Creative Commons Attribution license (http://creativecommons.org/licenses/by/4.0/). 